Article

\title{
Police Reform in a Post-Conflict Context: The Case of Solomon Islands
}

\author{
Sinclair Dinnen* and Danielle Watson **
}

\begin{abstract}
Police reform in much of the developing world reflects a preoccupation with either shifts away from paramilitaristic policing models or restoration of law and order in post-conflict societies. For many Pacific Island Countries (PICs), dialogue on reform reflects the prioritization of internal organizational restructuring and capacity building, with minimal emphasis on responding to ever-changing stakeholder demands. What is also common is for police reform efforts to closely align with prioritized focal areas of donor countries or powerful neighbours in developed countries with different contextual realities. Here we discuss police reform efforts in a PIC that has been the recipient of a major regional post-conflict state-building intervention and highlight the complexities specific to piecing together the police reform architecture. We also make reference to Solomon Islands to support our argument that problematic police reform can be largely attributed to focal imbalances between internal and external transformation agendas. The article concludes with a summary of the constraints associated with police reform in post-conflict contexts and recommendations for navigating the reform process.
\end{abstract}

\section{Introduction}

Police reform in much of the developing world has focused on shifts away from reactive policing models to more people-centred service-oriented approaches (Bazemore and Griffiths, 2003). Reform efforts in post-conflict contexts focus primarily on developing strategic and operational capabilities of police organizations (Goldsmith and Dinnen, 2007) and are largely shaped by external or unrelated foreign agendas concerned with crime, regional, and transnational security issues (Goldsmith and Sheptycki, 2007). Such models receive criticism for being rigid, one-dimensional, largely symptomatic, and primarily focused on responding to crime and conflict as opposed to engaging in partnerships to prevent or minimize acts of criminality and social disorder (Goldstein, 1990; Sheptycki, 1998; Watson and Kerrigan, 2018). What is also true of reform efforts in such contexts is a difficulty in developing effective, long-term solutions to the problems-such as conflict, distrust in judicial and police systems, institutional weakness, and/or social unrest-which initially led to the reform efforts.

\footnotetext{
*Department of Pacific Affairs, Coral Bell School of Asia Pacific Affairs, Australian National University, Canberra, Australia

**Lecturer and Coordinator - Pacific Policing Programme, School of Social Sciences, Faculty of Arts, Law and Education, University of the South Pacific, Laucala Campus, Fiji. E-mail: danielle.watson@usp.ac.fj
} 
In the Southwest Pacific, leading aid donors such as Australia and New Zealand have prioritized the maintenance of law and order in the region's island states. They acknowledge the fragility of some states and their susceptibility to internal security problems as well as possible threats to sovereignty posed by transnational crime and the shifts in the region's geopolitics (Walton and Dinnen, 2016). During the first decade of the new millennium, Australia adopted a more interventionist approach in its relations with its Pacific Island neighbours (Fry and Kabutaulaka, 2008), with significant resources invested in police reform, primarily in the fragile and conflict affected Melanesian territories. Solomon Islands received significant police reform assistance following an ethnic conflict which led to the effective collapse of government services and the rule of law. The Australian-led Regional Assistance Mission to Solomon Islands (RAMSI) was deployed in mid-2003 to help restore law and order, rebuild state agencies and revive the national economy. Conforming to other contemporary Western-led post-conflict interventions, these external efforts prioritized state-building, and, in particular, strengthening of domestic law enforcement and judicial agencies. A criticism raised at the time was that Australia's investment in police capacity building occurred with limited knowledge about the local impacts of these investments (Goldsmith and Dinnen, 2007). This suggests not only a need to re-evaluate the effectiveness of reform efforts, but a requirement to re-consider the applicability and sustainability of such undertakings.

The recent ending of the 14-year regional mission to Solomon Islands provides a timely opportunity to consider the challenges associated with international police reform interventions in post-conflict settings. Here, we draw on our own research and provide an overview of scholarly literature documenting different stages and dimensions of reform efforts under RAMSI. The lead author has undertaken extensive research in Solomon Islands over the past two decades into policing, justice, and security, while the second author conducts research on police/community relations in Polynesia and Micronesia, and coordinates the Pacific Policing Programme at the University of the South Pacific, which caters to 12 PICs. We elaborate on lessons from this research to situate it within larger discourses about police reform in post-conflict contexts. While we acknowledge the multifaceted and complex nature of police reform in such settings, our discussions focus on distinguishing among aspects of reform efforts aimed at organizational transformation, capacity development, and contextual appropriation, all of which feature as key areas in transformative police reform literature (Bazemore and Griffiths, 2003). We discuss SI's unique social, political and geographical context, and elaborate on reform undertakings, which sought to change, improve, and/or transform the RSIPF as a police organization.

\section{Solomon Islands-a contextual overview}

Solomon Islands consists of a double chain of six large islands and several hundred smaller ones, lying 1,800 kilometres off Australia's north-eastern coast. It shares similar social characteristics to its Melanesian neighbours, Papua New Guinea and Vanuatu, including high levels of socio-linguistic diversity. Between 60 and 70 languages are still spoken among a population of around 614,000. Prior to colonization, the archipelago's indigenous population lived in a patchwork of small, selfregulating societies scattered across the islands, engaging in subsistence agriculture and living according to local customary norms and practices.

The islands became a British protectorate in 1893 and were administered under a modestly resourced system of colonial government until they gained their political independence in 1978 (Dinnen 2008). Decolonization was accompanied by the establishment of the institutional trappings of modern statehood. However, these hastily assembled structures had shallow foundations in 
Solomon Islands society. The newly established state was weak institutionally and had limited reach beyond the national capital, Honiara. State consolidation has been complicated by various factors, including the country's archipelagic geography, social diversity, small formal economy, and a political culture characterized by patrimonialism and 'money politics' that has been lubricated by corrupt dealings in the logging industry (the main source of national revenue since the 1980s). Around $80 \%$ of citizens still live in rural villages where contemporary forms of 'community' are based on complex interplays of kinship and exchange relations, friendships, church membership, and myriad types of claims to customary land. Everyday justice and security needs continue to be managed informally in most rural and urban communities. These local approaches to justice and security vary but typically draw on multiple sources of authority, notably custom, state, and church (Allen et al., 2013).

The Royal Solomon Islands Police Force (RSIPF) is a small and urban-based police organization that performed adequately for most of the post-independence period. Before the outbreak of serious ethnic tensions in the late 1990s, there were few major law and order challenges. While there were growing problems of corruption, criminal violence and public order were not significant concerns in Honiara and other urban centres, while community-based approaches to dispute resolution and security provided for the needs of most rural-based citizens.

Immediately prior to the deployment of RAMSI in mid-2003, Solomon Islands had experienced several years of low-level conflict. The conflict, known locally as 'the tensions', involved armed skirmishes between rival ethnic militias from the main islands of Guadalcanal and Malaita. It led to the breakdown of government authority and service delivery, serious lawlessness in some areas and rapid economic decline. Ethnic divisions resulted in the effective collapse of the RSIPF, the sole coercive arm of the Solomon Islands state. The causes of the conflict were multiple and complex (Fraenkel, 2004; Moore, 2004; Allen, 2013). They included historical patterns of uneven development, internal migration and settlement, localized land disputes and contestation over benefits distribution from resource projects, the prevalence of subnational identities and political agendas, as well as the exigencies of patronage politics in the context of a larger fiscal crisis in the late 1990s.

One of the ethnic militias in collaboration with the paramilitary Police Field Force (PFF) raided the national armoury and mounted a de facto coup in June 2000. Despite the signing of a peace agreement between the rival militias in October 2000, the country remained militarized and militants and elements of the police continued to engage in collective and opportunistic violence. These events profoundly undermined public confidence in the RSIPF (Dinnen and Allen, 2013). By 2003, it was clear that authorities in Honiara were incapable of resolving the national crisis without some kind of external circuit-breaker. The Australian-led regional mission was deployed in mid-2003 under the auspices of the Pacific Islands Forum (PIF), the premier regional political grouping, with the aim of restoring security, rebuilding government, and reviving the national economy.

\section{Policing Solomon Islands post-conflict}

Unlike police reform in non-conflict contexts, reform efforts in SI were part of a major regional intervention following requests from beleaguered authorities in Honiara. RAMSI was a police-led mission, with the Participating Police Force (PPF) in the lead, rather than the mission's military contingent. The PPF was responsible for restoring security and rebuilding the RSIPF. The prominence of policing in the architecture of the mission reflected international thinking about the importance of restoring law and order as a prerequisite for long-term stability and development. 
The overall size of the PPF fluctuated over the 14-year mission, peaking at around 325 officers in 2007 and steadily declining in the latter stages. Even with these fluctuations, the PPF represented a substantial intervention in a small, local police organization of around 1,000 personnel. While the majority of the PPF were Australians and New Zealanders, on average around one-fifth came from 13 Pacific Islands police forces-Papua New Guinea, Fiji, Cook Islands, Palau, Kiribati, Marshall Islands, Nauru, Samoa, Tonga, Vanuatu, Nuie, Tuvalu, and Federated States of Micronesia (Putt et al., 2018).

Codenamed Operation Helpem Fren ('Helping a friend'), the mission evolved over time in response to changing circumstances and institutional learning. PPF personnel shifted regularly between executive policing and working as advisers. In the former role, PPF officers exercised police powers under Solomon Islands law, while in the latter they engaged primarily in training and capacity building activities with their RSIPF counterparts. An end-of-mission report identified a number of key phases in RAMSI's evolution (SIG/RAMSI, 2017, pp. 27-28):

- Intervention and stabilization (2003-2004)

- Institutional Strengthening (2004-2005)

- Capacity development amid political volatility (2006-2008)

- Re-energised partnership towards RAMSI's transition (2009-2013)

- Police development and drawdown (20132017)

The early phase of RAMSI was primarily about restoring security. This was critical to ensuring the conditions necessary for the longer-term statebuilding enterprise, including police reform. Security was restored rapidly and peacefully. Joint PPF/RSIPF patrols appeared on the streets of Honiara within hours of the mission's arrival, while provincial police posts were quickly established in each of Solomon Islands nine provinces.
By the end of a month-long amnesty around 3,730 illegal firearms had been surrendered or collected, amounting to an estimated $90-95 \%$ of the country's stockpile (Muggah, 2004). Key militia leaders surrendered or were apprehended by the PPF. These early successes were RAMSI's most tangible accomplishment.

The task of cleansing the ranks of the RSIPF also began early. A priority was to disband the notorious STAR Division which included members of the paramilitary PFF that had been involved in the raids on the national armoury and coup of June 2000. Identifying compromised officers involved a process of vetting, recertification and internal investigation of RSIPF personnel (Dinnen et al., 2006, pp. 98-99). 'Vetting-before-reform' was based on the assumption that the organization needed to be thoroughly cleansed before the reform process could proceed. By February 2004, over 50 RSIPF officers, including two deputy commissioners, had been arrested and charged with over 285 offences, including for serious crimes such as murder, robbery, assault, intimidation, and corruption. More than a quarter of the RSIPF workforce had resigned or been removed by the end of the first year (Putt et al., 2018, p. 29).

Strategic leadership in this highly sensitive work was provided by a small group of experienced Australian police with specialist skills and training. A balance had to be struck between a comprehensive root and branch institutional change and the need to retain sufficient numbers of experienced officers in middle and senior ranks to help train and lead newly recruited personnel, and provide some continuity in the organization. Internal disciplinary and accountability systems also had to be revitalized and strengthened, and rigorous processes of merit-based recruitment introduced to begin replenishing the RSIPF's depleted ranks. An average of 70 officers were recruited each year from 2003 to 2013. Around 63\% of the membership of the RSIPF at the time of RAMSI's deployment in mid-2003 had left the organization by mid-2013 (Fraenkel et al., 2014, p. 37). 
The mission inevitably experienced set-backs. These included serious public disturbances in Honiara in April 2006 following national elections and the subsequent deterioration of bilateral relations between Solomon Islands and Australia. Mission police were caught off-guard and reinforcements from Australia, New Zealand, and Fiji were needed to restore order. The bilateral relationship deteriorated following the election of Manasseh Sogavare as Prime Minister. As a staunch nationalist and critic of the mission, he sought to reassert his government's control over RAMSI in the face of what he considered as Australia's dominant influence. This provoked strong resistance from the Australian government and there followed a period of acrimonious exchanges that included Sogavare's effective sacking of the Australian officer serving as RSIPF commissioner. Relations eventually improved following changes of government in both countries in late 2007. Despite these political ructions at the highest levels, RAMSI's everyday work remained relatively unaffected.

Whereas the mission's earlier operational (executive policing) phases produced quick and quantifiable outcomes in the form of arrests, weapons surrendered, and charges laid, the capacity development phase (police reform) was more challenging and intrinsically difficult to measure. The slow and uneven progress of this work, common to all international police-building, was also a reflection of the low starting base presented by the condition of the RSIPF when the mission commenced. Compounding the difficulties was the slow task of recruiting and training new personnel, as well as the lingering effects of divisions in some parts of the RSIPF associated with the earlier tensions (Braithwaite et al., 2010, p. 59).

\section{Organizational transformation and capacity development efforts}

Police reform efforts generally prioritize capacity building through organizational restructuring, reconstructing institutional remit and development of human resources. Such efforts aim to strengthen the most visible arm of government to execute its national security mandate. In a postconflict setting like Solomon Islands, where the machinery of government, including the police, had effectively collapsed, the rebuilding exercise provided an opportunity to consider what kind of policing organization was most suited to the country's specific context and needs and that would avoid the risk of future collapse. The practical realities of such exercises, however, with their heavy dependence on external technical expertise, funding, and other support, is that they are more likely to be shaped by the experiences, expertise and institutional priorities and preferences of the external actors, rather than being informed by the exigencies of the local context (Dinnen and McLeod, 2009). Reform agendas under these circumstances are not necessarily driven by a longer term vision of a transformed organization that can be sustained without external support. Instead, the emphasis on implementing something 'new' in developing country contexts usually refers to something 'borrowed' (Ellison and Pino, 2012; Hughes et al., 2013). Here we present internal police reform under RAMSI and discuss its implications for policing in Solomon Islands. We discuss for key areas_-organizational restructuring; policy adoption, adaptation, and implementation; state legitimacy versus service provision; and reform efforts and organizational culture-specific to transformative police reform in developing country contexts.

\section{Organizational restructuring}

For many members of the PPF, the switch from executive policing to capacity development was extremely challenging. Instead of the proactive, problem-solving approach required by their home police organizations, they were now expected to stand back and mentor local officers in how to do the job in a local context that was unfamiliar to 
most. What some observers have described as the police-building paradox required the PPF to choose between their mentoring roles or actually getting the job done when their RSIPF counterparts experienced difficulties, with the temptation to do the work themselves often proving overwhelming (Harris, 2010). The distribution of capacity development skills among the PPF also varied and in the early days there was little focus on this area in either the pre-deployment training or recruitment processes. At that time, the priority was as much about securing the required number of PPF personnel as on finding people with the right skill sets. Establishing effective relationships between international and local police was also affected by the relatively short postings of PPF officers in the initial phases, resulting in longer postings for certain positions as the mission evolved.

Transferring responsibility for frontline policing from the PPF to the RSIPF occurred in Honiara in 2011 and elsewhere from 2013 during a prolonged transitional phase. The PPF gradually withdrew from provincial police posts and commenced a series of intensive training programs with the RSIPF to enable the latter to assume full responsibility for policing. Components of a final Drawdown Strategy included training and support focused on public order management, operational safety training and limited rearmament of the RSIPF. Complete control of policing was officially handed back to the RSIPF with the ending of the 14-year and AUD 3 billion mission on 30th June 2017. While RAMSI has gone, Australia and New Zealand continue to provide substantial bilateral assistance to the RSIPF, including through incountry police advisers. While numbers fluctuate, there are currently eight New Zealand police advisers and up to 44 Australian advisers in Solomon Islands. The New Zealand contribution is focused on crime prevention and community engagement, while Australian assistance spans a broad spectrum of organizational and individual capacity-building with advisers working across the whole RSIPF. In addition, Australia and Solomon Islands signed a security treaty in 2017 that allows for a rapid Australian response in the event of future natural disasters or outbreaks of civil unrest, including the deployment of defence, police, and civilian personnel in an operational capacity (Australian Treaties 2018). Since the mission withdrew, there have been no major security or public order incidents and popular confidence in the RSIPF has gradually improved, although resource constraints remain a serious challenge.

\section{Policing policy adoption, adaptation, and implementation}

Reform led by external donors tends to prioritize the projection of foreign standards of appropriateness to local contexts. There is a well-known proclivity to transfer knowledge from their own context (which in most instances are believed to be superior) and a predisposition on the part of international policing actors to build in their own image, thereby excluding alternative possibilities (Dinnen and Allen, 2013). The approach adopted by the RSIPF to improve its damaged relations with Solomon Islands communities exemplifies this tendency. Here we reference the Solomon Islands Crime Prevention Policy as an illustration.

As part of organizational reform, the RSIPF has implemented a National Prevention Strategy modelled after the New Zealand Police's Crime Prevention Strategy. While commendable as a proactive, positive, and progressive operating strategy, contextual variables necessitate further consideration about adaptation and implementation for this vision of community policing to be actualized. In an initial evaluation of the strategy in 2018 commissioned by the RSIPF and funded by the AFP, shortcomings identified included a failure to fully integrate non-RSIPF stakeholders, lack of support from other agencies, policy adaptation based solely on the Honiara context (which has significantly different circumstances to the provinces), poor recognition of traditional authority structures and inadequate training/preparation of 
frontline officers to action policy (Crime Prevention Evaluation Strategy, 2018). The narrow focus on security concerns in many such reform undertakings highlights the areas of strategic importance to the external drivers of change, which do not necessarily align with those of local stakeholders. For example, a focus on increased arrest rates or on the upskilling of police senior management does not address the issue of poor visibility of frontline officers or unsatisfactory police response times. Likewise, the focus on policing urban contexts, notably Honiara, neglects the very different circumstances in the rural settings where the bulk of the local population live. All of the areas identified in the review, indicate shortcomings that require a significant commitment of monetary and other resources, a commitment which continues to be met by mainly Australian and New Zealand aid to Solomon Islands.

Adopting international policing models as a strategy for successful reform in post-conflict or otherwise fragile local contexts is highly problematic. Policies borrowed from abroad are likely specific to the context within which they were developed, aligned to a specific dimension on the organizations strategic plan and are likely intended to address issues specific to the locality, which resulted in its creation. They are also likely to reflect the different fiscal and governmental conditions prevailing in donor countries. More careful consideration needs to be given to the social, economic, and other environmental features of the recipients of these institutional transfers. In the Solomon Islands case, this included the prevalence of normative and regulatory pluralism throughout the archipelago, whereby customary, church and other non-state actors played a significant part in providing everyday policing and dispute resolution services at local levels, alongside those provided by the RSIPF and formal justice system. There are also the significant constraints on the fiscal and administrative capacity of the Solomon Islands government and the difficulties of ensuring adequate RSIPF coverage across the length and breadth of country's challenging archipelagic geography. Examples of deliberate attempts to design reforms on the basis of distinctive features of the local 'operating environment' are comparatively rare in the case of large externally driven police reform exercises like RAMSI, and are often treated as peripheral within the overall reform exercise. An important though modest exception was the Community Officer Pilot Project, which was launched in 2009 with support from the Australian Federal Police (AFP). Under this scheme, Community Officers (COs) were appointed by the RSIPF in close consultation with community leaders in selected rural locations in five different provinces. These individuals were unsworn civilians of good community standing who were issued with a basic uniform ( $t$-shirt and cap) and given some very basic police training. Their role was to liaise with regular police during the latter's very rare visits and more generally to work closely with community leaders in relation to everyday dispute resolution and community safety. The limited presence of uniformed police in these areas enhanced the possibility of conflict escalation in the case of relatively minor disputes and infractions, particularly in places where traditional authority was under considerable stress from rapid socio-economic change. The appointment of COs was in part inspired by an older administrative figure-the area constable-who had played an important role liaising between community leaders and government authority during the late colonial period, as well as helping to manage local dispute resolution. An evaluation of the $\mathrm{CO}$ pilot involving one of the authors heard overwhelmingly positive assessments by members of the relevant communities. While remaining disappointed by the irregularity of visits by the RSIPF, the presence of the $\mathrm{CO}$ was viewed by many as contributing to improved levels of community safety and deterring criminal behaviour, suggesting that they had a 'shadow of law' effect in these communities. More generally, the presence of the $\mathrm{CO}$ was perceived as a tangible connection, however tenuous, with the 
broader government and justice system that many villagers felt had been absent in recent years. Thus, one, interviewee remarked that the CO marked the 'return of government', while another commented that 'the CO makes us feel like the government is now with us' (Dinnen and Haley 2012, p. 30). Despite the documented success of this pilot and the potential insights it provided into an affordable and socially appropriate approach to policing in rural areas, it proved to be a relatively shortlived experiment and was overshadowed by the larger police reform exercise with its singular focus on restructuring the RSIPF.

\section{State legitimacy versus service provision}

Externally driven police reform in post-conflict contexts also tends to prioritize state building over efforts to improve police legitimacy. Teskey identifies three key pillars critical to state building-political legitimacy, institutional capacity, and functional authority (Teskey, 2012). While these areas are acknowledged in donor mandates, they usually translate to one of two realities: inadequate focus on difficult areas requiring longterm attention or large-scale borrowing and adaption from dissimilar foreign contexts. What is common is a narrow emphasis on institution-building and strengthening, which almost invariably takes precedence over more complex and costly initiatives involving stakeholder participation geared towards long-term solutions to identified problems. The RAMSI mandate prioritized police building as opposed to improved service provision with a focus on improved police/community relations.

Echoing critiques in the international scholarly literature, critical studies of police reform in SI highlight the deficit orientation of those engaged in capacity building. Such an orientation emphasized the shortcomings of the RSIPF and assumed that the best way to fix these lay in emulating 'successful' foreign police forces, such as those in Australia and New Zealand. Little effort was made to look for local strengths in either the RSIPF or broader Solomon Islands society that could be built upon to develop an effective and sustainable policing approach suited to this particular context (Harris, 2010). This included neglecting the vibrant constellations of community-based actors and local mechanisms that, in practice, constitute significant co-providers of 'policing' and 'justice' for Solomon Islands dispersed and predominantly rural-based population. Access to state justice agencies continues to be a challenge for many Solomon Islanders, while priority concerns with land disputes and logging remain largely beyond the remit of the police organization. Improving policing in the country's complex and diverse social landscape and fragmented geography requires more deliberate efforts to bridge the gaps between state authority, as represented by the RSIPF, and the dynamic (non-state) systems of authority, leadership and regulation that prevail at local levels throughout the archipelago. These efforts are also critical to the restoration of legitimacy and public confidence in the RSIPF.

\section{Reform efforts and organizational culture}

The impact of reform efforts on internal organizational culture is an under-discussed issue with the potential to significantly impact organization functionality. Officers' feeling of belonging, resentment towards administration or shared perceptions about being 'othered' influences what eventually becomes organizational culture. While not as challenging as in many of the larger UN missions, the work of the PPF was also complicated owing to members coming from different countries and police organizations and the challenges of working in a different national context. Negotiating linguistic and cultural differences was an issue for some PPF members who were not from the Pacific Islands, particularly those posted to provincial police posts. PPF members from the Pacific Islands generally proved more adept at communicating and interacting with Solomon Islanders, whether RSIPF officers or members of 
the wider community (Putt et al., 2018). Many of these issues were recognized as the mission progressed and resulted in adaptations to training and recruitment processes (Braithwaite et al., 2010).

Disparities in their organization and the resources available to the PPF and RSIPF, including in their respective conditions of service, contributed to the popular perception of two separate police forces operating in Solomon Islands for much of the mission's duration. While the reality of two separate police forces was necessary in the initial phase of the mission owing to the tasks of restoring law and order and cleaning up the RSIPF, it became increasingly counter-productive as the PPF's focus switched to empowering the RSIPF to resume full responsibility for policing in the later stages of the mission. The early success of the PPF in their executive policing role served to highlight the flaws of the RSIPF and an unfavourable comparison between the two forces proved to be an enduring one among Solomon Islanders. Ironically the continuing presence of the PPF, particularly in the later stages of the mission, served to undermine public confidence in the very police organization whose capacity they were simultaneously trying to build (Dinnen and Allen, 2013).

At its height reform efforts in SI saw a 1: 3 ratio of foreign to local officers with foreign officers initially occupying the majority of executive leadership and command positions and local officers relegated to frontline operational support roles. The high number of international officers inevitably had some 'crowding out' effects on local counterparts, including in terms of motivation and morale (Dinnen and Allen, 2013, p. 230). The deficit view of the RSIPF, mentioned above, with its focus on the deficiencies of the local police organization reinforced this further.

Policing in SI since 2003 has been heavily dependent on external financial support from Australia and New Zealand (Haque and Greig, 2011), with RAMSI estimated to have provided approximately two-thirds of the total cost of policing. In the post-RAMSI period, the RSIPF continues to receive significant levels of external support from the Australian government (ASIAP, 2017). Concerns have been expressed over the fiscal sustainability of the RSIPF and other Solomon Islands law enforcement frameworks if donor support were to be withdrawn or significantly reduced.

\section{Considering contextual appropriations and police reform}

As indicated earlier, police reform efforts in SI have been largely focused on institutional capacity building. There are still concerns that such efforts do not sufficiently extend beyond the formal police organization to engage with the full spectrum of actors involved in the provision of everyday security and dispute resolution. In this sub-section, we discuss external factors likely to impact police service provision and highlight the need for such factors to be considered in 'function over form' reform-related undertakings.

\section{Non-alignment of parallel authorities}

Organizational reform efforts prioritized the introduction of structures, institutional legitimacy, transparency, and standards of accountability. These are usually reflected in the introduction or revision of existing mandates and policy. Unlike some contexts in the Global North, where the state claims to exercise a monopoly over security service provision and upholding law and order, in the SI context, order has always been co-produced by multiple groups, with most areas outside Honiara and the small provincial capitals having relative autonomy in the provision of everyday security and order maintenance. Solomon Islands is not unique among post-colonial states in its inability to provide access to justice and policing to all its citizens (Baker, 2010). The plurality of justice and policing providers in practice, including the hybrid approaches prevailing at local levels in both rural and urban areas, can present a challenge for police. 
Similar to other parts of the world where informal policing and justice provision are prevalent, there are very real concerns about the quality of 'justice' on offer through many of these informal approaches. Among these are concerns about potential human rights abuses, particularly in respect of vulnerable groups, such as women, who are often seriously disadvantaged in 'traditional' power hierarchies and social relations. An example is seen with the customary handling of domestic disputes, where the rights of women are often neglected or subordinated to those of more powerful men. These concerns resonate with wider debates in international literature around the difficult relationship between informal regulatory orders, particularly those premised on appeals to custom, faith and tradition, and formal global human rights norms (NZ Law Commission, 2006). Top-down reform efforts non-cognizant or unfamiliar with local realities run the risk of replicating failed colonial interventionist approaches adapted from the Global North and unsuited to Southern contexts.

\section{Lack of public trust}

A matter critical to successful police reform is the establishment of a trustworthy institution (Stoutland, 2001; Goldsmith, 2005). Public trust in the police in inextricably impacted by police ability to provide basic security for citizens (Goldsmith 2003, 2005). In post-conflict societies such as SI, distrust in the police is not uncommon due to what Goldsmith (2005, p. 444) describes as its 'highly contingent character in most social relations'. State policing broke down altogether during Solomon Islands tensions with elements of the RSIPF playing partisan roles and engaging in serious criminality. The tensions period (1998-2003) and unrest significantly damaged public trust in the police as officers openly expressed loyalties to ethnic groupings and militias over their professional mandated responsibilities and, in some cases, engaged in collective and opportunistic violence. While the RSIPF has been substantially rebuilt over the intervening 14-years with significant changes in personnel, the legacy of distrust remains and is unlikely to be overcome through a narrow and technical focus on capacity-building activity with the RSIPF. More profound changes are required to develop a form of policing appropriate to the Solomon Islands environment, which would entail a more networked approach inclusive of other sources of regulation and that is capable of reaching beyond the urban enclaves where formal police resources remain concentrated.

As we have seen, the police reform exercise undertaken under the auspices of RAMSI involved significant participation from foreign actors. In the post-RAMSI present, the continuing dependence on substantial external police assistance, including the possibility of further intervention under the security treaty with Australia, underlines the fragility of the reform efforts. To date, the RSIPF continues to be headed by a seconded officer from the AFP, while a small contingency of officers from donor countries remain in SI in advisory roles. This also raises questions about whether the assumed confidence in police is reflective of trust in the ability of local or foreign state actors.

\section{Recommendations for navigating reform}

As many scholars and policy makers have attested, there is no correct formula for international and domestic police reform. What is also true is that there is no right model for reform that is transferable to contexts not accounting for the creation of the model. What accounts for policing 'best practices' in one context cannot be assumed to be internationally transferable, specifically in contexts with distinct colonial legacies, major problems of underdevelopment, and high levels of normative and regulatory pluralism (Goldsmith and Dinnen, 2007). Interestingly, recent years has seen a revival 
of interest in the Community Officer concept in several rural provinces where rapid social and economic change, often involving commercial resource extraction, have generated an increase in disputation and crime. Adaptations of the Community Officer model have emerged as a way in supplementing the modest RSIPF presence and also of responding to the distinct policing needs in different rural communities (Horscroft, 2018). While modest in scale, these kinds of local policing experimentation have potential for contributing to the fostering of productive relations across the multiple social orders and sources of authority that are typically found in many post-conflict and fragile contexts.

Despite the necessity of police reform, particularly in developing and post-conflict contexts, ambitious police-building undertakings like RAMSI cannot on their own serve as the sole strategy to address issues related to the maintenance of peace, law, and order in any society. In post-conflict Solomon Islands, restoring sustainable peace and stability requires attention to a complex range of social, economic, and political challenges going well beyond a narrow focus on policing and security. Police reform efforts need to demonstrate flexibility, reflexivity, and adaptability. In the SI context, there is also the need to prioritize transformations that lead to a model of policing that facilitates working closely with communities and local leadership structures. This is, of course, not to suggest that the significant reform efforts undertaken during RAMSI are irrelevant. Instead, we suggest the need for transformation to be informed by better understandings of local social, cultural, and political circumstances and needs and for strategies specific to the identified challenges to be developed.

It is also necessary to consider that security priorities between police reformers and the larger populace may differ. Reform efforts in SI, like many other contexts, have prioritized capacity building and addressing serious crimes or possible threats to national security and the larger society, as opposed to issues viewed as more mundane or trivial which usually relate to local transgressions impacting community welfare and cohesion. To ignore non-priority issues will work in the disservice of police legitimacy, thus rendering identified prescriptions ineffective or limited or symptomatic.

\section{References}

Allen, M., Dinnen, S., Evans, D., and Monson, R. (2013). Justice Delivered Locally - Systems, Challenges and Innovations in Solomon Islands. Washington DC: World Bank, Justice for the Poor, Research Report, July 2013, pp. 1-92.

Allen, M. G. (2013). Greed and Grievance: Ex-Militants' Perspectives on the Conflict in Solomon Islands 1998-2003. Honolulu, HI: University of Hawai'i Press.

Australia-Solomon Islands Aid Partnership (ASIAP), (2017-2020). http://dfat.gov.au/about-us/publications/ Documents/australia-solomon-islands-aid-partnership2017-2020.pdf (accessed 19 April 2019).

Australian Treaty Series. (2018). Agreement between the government of Australia and the government of Solomon Islands concerning the basis for deployment of police, armed forces and other personnel to Solomon Islands. http://www.austlii.edu.au/au/other/dfat/treaties/ ATS/2018/14.html (accessed 19 April 2019).

Baker, B. (2010). 'Linking State and Non-State Security and Justice'. Development Policy Review, 28(5): 597-616.

Bazemore, G. and Griffiths, C. (2003). 'Police Reform, Restorative Justice and Restorative Policing'. Police Practice and Research, 4(4):335-346.

Braithwaite, J., Dinnen, S., Allen, M., Braithwaite, V., and Charlesworth, H. (2010). Pillars and Shadows - Statebuilding as Peacebuilding in Solomon Islands. Canberra: ANU E Press.

Dinnen, S. (2008). 'The Solomon Islands Intervention and the Instabilities of the Post-Colonial State'. Global Change Peace \& Security, 20(3):339-355.

Dinnen, S., McLeod, A., and Peake, G. (2006). 'Police-Building in Weak States: Australian Approaches in Papua New Guinea and Solomon Islands'. Civil Wars, 8(2):87-108.

Dinnen, S. and Haley, N. (2012). Evaluation of the Community Officer Project in Solomon Islands. Washington DC: World Bank, Justice for the Poor Programme, Research Report, May 2012. http://documents.worldbank. org/curated/en/409581468303004515/Evaluation-of-theCommunity-Officer-Project-in-Solomon-Islands (accessed 19 April 2019). 
Dinnen, S. and Allen, M. (2013). 'Paradoxes of Police-Building in Post-Colonial Societies: Solomon'. Policing and society, 23(2):222-242.

Dinnen, S. and McLeod, A. (2009). 'Policing Melanesia International Expectations and Local Realities'. Policing \& Society, 19(4):333-353.

Ellison, G. and Pino, N. W. (2012). Globalization, Police Reform and Development. Doing It the Western Way? Basingstoke, UK: Palgrave Macmillan.

Fraenkel, J. (2004). The Manipulation of Custom: From Uprising to Intervention in the Solomon Islands. Wellington, NZ: Victoria University Press.

Fraenkel, J., Madraiwiwi, J., and Okole, H. (2014). The RAMSI Decade: A Review of the Regional Assistance Mission to Solomon Islands, 2003--2013. Honiara: Solomon Islands Government.

Fry, G. and Kabutaulaka, T. (2008). 'Political Legitimacy and State-Building Intervention in the Pacific'. In Fry, G. and Kabutaulaka, T., (eds), Intervention and State-Building in the Pacific - the Legitimacy of 'Cooperative Intervention. Manchester: Manchester University Press, pp. 1-46.

Goldsmith, J. (2003). 'The Road to Meaningful Reform: A Conversation with Oregon's John Kitzhaber'. Health Affairs, 22(1):114-124.

Goldsmith, A. (2005). 'Police Reform and the Problem of Trust'. Theoretical Criminology, 9(4):443-470.

Goldsmith, A. and Dinnen, S. (2007). 'Transnational Police Building: Critical Lessons from Timor-Leste and Solomon Islands'. Third World Quarterly, 28(6): 1091-1109.

Goldsmith, A. and Sheptycki, J. (eds) (2007). Crafting Transnational Policing: Police Capacity-Building and Global Policing Reform. Oxford: Hart Publishing.

Goldstein, H. (1990). Excellence in Problem-Oriented Policing. New York NY: Police Executive Research Forum.

Haque, T. and Greig, F. (2011). Increasing the Participation of Women Entrepreneurs in the Solomon Islands Aid Economy. Washington DC: World Bank.

Harris, V. (2010). 'Building on Sand? Australian Police Involvement in International Police Capacity Building'. Policing \& Society, 20(1):79-98.

Horscroft, V. (2018). 'Isolation, opportunity and justice in Solomon Islands'. October 30, 2018. DEVPOLICYBLOG. Canberra: Development Policy Centre, Australian National University. http://www.devpolicy.org/isolation-opportunityjustice-solomon-islands-20181030/ (accessed 19 April 2019).

Hughes, B., Hunt, C. T., and Curth-Bibb, J. (2013). Forging New Conventional Wisdom beyond International
Policing. Learning from Complex Political Realities. Leiden \& Boston: Martinus Nijhoff Publishers.

Moore, C. (2004). Happy Isles in Crisis: The Historical Causes for a Failing State in Solomon Islands, 1998-2004. Canberra: Asia Pacific Press.

Muggah, R. (2004). 'Diagnosing Demand: assessing the Motivations and Means for Firearms Acquisition in the Solomon Islands and Papua New Guinea'. State Society and Governance in Melanesia, Australian National University, Discussion Paper 2004/7.

NZ Law Commission. (2006). Converging Currents: Custom and Human Rights in the Pacific. Wellington, NZ: NZ Law Commission.

Putt, J., Dinnen, S., Keen, M., and Batley, J. (2018). The RAMSI Legacy for Policing in the Pacific Region. Department of Pacific Affairs, Australian National University, Research Report January 2018.

Royal Solomon Islands Police Force Crime Prevention Strategy Evaluation Report. (2018). Crime Prevention Strategy Evaluation April - July 2018.

Sheptycki, J. W. (1998). 'The Global Cops Cometh: Reflections on Transnationalization, Knowledge Work and Policing Subculture'. The British Journal of Sociology, 49(1):57-74.

Solomon Islands Government (SIG) and RAMSI. (2017). Regional Assistance Mission to Solomon Islands (RAMSI) 2003-2017. A Joint Report by the Solomon Islands and RAMSI on the 14-year intervention. Solomon Islands: Officer of the Prime Minister.

Stoutland, S. E. (2001). 'The Multiple Dimensions of Trust in Resident/Police Relations in Boston'. Journal of Research in Crime and Delinquency, 38(3):226-256.

Teskey, G. (2012). 'State-Building and Development: Getting beyond Capacity'. In Jones-Parry, R. (ed.), Commonwealth Good Governance 2011/12. London: The Commonwealth Secretariat, pp. 44-48.

Walton, G. and Dinnen, S. (2016). The dark side of economic globalisation: politics, organised crime and corruption in the Pacific. Development Policy Centre, Australian National University, Discussion Paper 48. SERIES ISSN 2206-303X.

Watson, D. and Kerrigan, D. (2018). 'Crime, Criminality, and North-to-South Criminological Complexities: Theoretical Implications for Policing "Hotspot" Communities in "Underdeveloped" Countries'. In Carrington, K., Hogg, R., Scott, J., and Sozzo, M. (eds), The Palgrave Handbook of Criminology and the Global South. Palgrave Macmillan: Basingstoke, UK, pp. 611-632. 